\title{
APPENDIX 1 \\ MACROBENTHIC COMMUNITY STRUCTURE AND DISTRIBUTION IN THE ZWIN NATURE RESERVE (BELGIUM AND THE NETHERLANDS)
}

Accepted for publication as:

\author{
Van Colen C., Snoeck F., Struyf K., Vincx M., Degraer S. (in press) \\ Macrobenthic community structure and distribution in the Zwin nature reserve \\ (Belgium and the Netherlands) \\ Journal of the Marine Biological Association of the United Kingdom
}

\section{Abstract}

Distribution and structure of intertidal macrobenthic communities in the Zwin nature reserve, a lagoonal inlet consisting of marsh and tidal flat habitats, was investigated using univariate and multivariate analyses. Macrobenthos community structure was related to environmental characteristics and discussed in the framework of the implemented extension of the nature reserve. Based on explorative multivariate techniques, five different sample groups (SGs) were distinguished, which were, in general, located in different habitats of the Zwin nature reserve. The ecologically most important SGs, consisting of the highest macrobenthic density, diversity and highest densities of Nereis diversicolor and Scrobicularia plana, important prey species for wading birds and fish occurred in the deep tidal inlet channels. This habitat was characterized by fine to medium sand sediment and strong tidal currents, guaranteeing water renewal at each high tide. Other SGs were found in less and erratically submersed and thus stressed areas (i.e. tidal pond, salt pans and shallow flats). These assemblages 
were characterized by typical r-strategists (i.e. Capitella capitata and Polydora cornuta) and typical supralittoral, mobile species (i.e. Orchestia gammarellus and Collembola spp.). Being ecologically most important, the extension of wide, tidal creeks should be a prime target within the future development and management of the nature reserve.

Keywords: Macrobenthic community structure and habitat preferences, Zwin nature reserve, Intertidal habitat

\section{Introduction}

Estuaries and their adjacent intertidal habitats fulfil several important ecosystem functions (e.g. high productivity, nursery and feeding habitats for epibenthic fishes, crustaceans and birds) and services (e.g. pollution filter, counteracting coastline erosion) (McLusky \& Elliott 2004). Consequently many of these habitats are incorporated into nature reserves and designated as Special Areas of Conservation (SACs) according to the EU Habitats Directive (Anon. 1992). However, during the last 4 decades, coastal and estuarine ecosystems have been exposed to enhanced anthropogenic nutrient inputs and have been heavily exploited (e.g. dredging for building harbours or aggregate extraction, fishing, tourism) resulting in a general decrease in quality of these ecosystems (Bachelet et al. 2000, Diaz 2001, Wolanksi 2007). For instance, 2500 hectares of tidal flat and marsh habitats have been lost in the Schelde estuary (the Netherlands) since 1900, mainly due to land reclamation, deepening of the shipping channel and reinforcement of dykes (Eertman et al. 2002). To comply with the Water Framework Directive (WFD, Anon. 2000), the Flemish and Dutch governments have proposed to extend the Zwin nature reserve with 120 to 240 hectares of marshes and tidal flats, to be taken from the adjacent, formerly reclaimed polders. The Zwin nature reserve is a lagoonal inlet (i.e. seawater enters inlets on each tide), that has achieved an international reputation because its function as 
important breeding and wintering habitat for birds, especially waders (Struyf \& Degraer 2003).

Since macrofauna is essential for tidal flat ecosystem functioning as food resource (e.g. Cramp \& Simmons, 1977: (wading) birds; Hampel et al. 2005: fish) and nutrient cycling (McLusky \& Elliott 2004, Wolanski 2007), knowledge on the structure and distribution of the macrobenthic community in the present Zwin nature reserve is essential as a baseline for the appropriate design and evaluation of the implemented restoration project. However, at present, knowledge on macrobenthic community structure and distribution patterns is lacking. Benthic research in the Zwin nature reserve has formerly focused solely on nekton communities of the tidal creeks (Hampel et al. 2004, 2005) and the effects of emersion on macrobenthos in one selected tidal creek (Van Colen et al. 2006). The aims of this study were therefore to describe the macrobenthic spatial structure in terms of diversity, abundance, and their relation with the environmental characteristics in the Zwin nature reserve.

\section{Materials \& methods}

\section{Study area, sampling and laboratory treatment}

The Zwin nature reserve $\left(51^{\circ} 21^{\prime} \mathrm{N}, 3^{\circ} 22^{\prime} \mathrm{E}\right)$ extends $2.3 \mathrm{~km}$ along the North Sea coastline and is situated along the southern shore of the Schelde estuary mouth at the Belgian-Dutch border. It has a total surface area of 158 ha and comprises of dunes, salt marshes, salt pans, a constructed tidal pond and two large inlet channels with adjacent tidal flat -and creek systems (Fig. 1). 


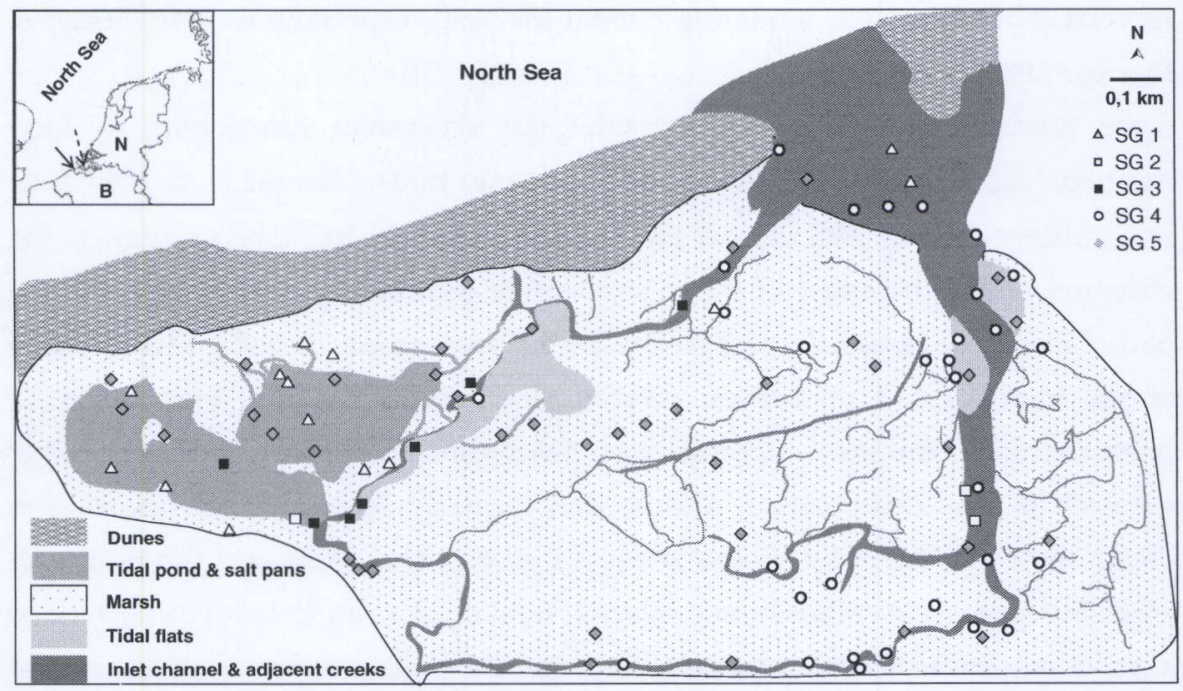

Fig. 1. Location of the Zwin nature reserve (solid arrow), at the mouth of the Schelde estuary (dashed arrow), along the southern shore (Belgian $(B)$ - Dutch $(N)$ border). Sampling stations are indicated by their sample groups (SG 1-5), distinguished by the multivariate analyses.

In Autumn 2003, at low tide, unreplicated macrobenthos samples were collected with a stainless corer (ø $12.5 \mathrm{~cm}$; penetration depth: $40 \mathrm{~cm}$ ) from 104 randomly selected intertidal locations. Samples were sieved over a $500 \mu \mathrm{m}$ mesh sized sieve and the residual was fixed and preserved with a $8 \%$ formaldehyde-seawater solution. All macrofauna was sorted, identified to the species level and counted except for nematodes. Oligochaetes were only partly identified to species level: a set of 730 oligochaetes was randomly selected from the samples for species identification. This set allowed to identify the oligochaete species list of the Zwin nature reserve, but oligochaetes were truncated for all further analyses. Species were classified into functional groups according to their feeding guilds (surface deposit feeders, subsurface deposit feeders, suspension feeders, omnivores and scavengers), based on available literature (Fauchauld \& Jumars 1979, Ysebaert et al. 2003, Volkenborn \& Reise 2007). Species belonging to more than one feeding guild were assigned to their most common feeding mechanism. 
At each location, (1) sediment characteristics and (2) intertidal elevation relative to mean high water tide level (MHWS, i.e. marsh border)) were measured. The distance below MHWS only gives a relative indication of the tidal position of the sampling location within the Zwin nature reserve (e.g. deep inlet channel, steep vs. shallow creeks, flats). Given the highly diverse geomorphology of the Zwin nature reserve, the relative intertidal elevation does not allow to calculate ecologically more relevant - submersion and emersion times. Samples for grain size distribution of the top $10 \mathrm{~cm}$ were collected using a $5 \mathrm{~cm}$ inner diameter perspex corer and analysed for median grain size and mud content (volume percentage $<63 \mu \mathrm{m}$ ) with a LS Coulter particle size analyser.

\section{Data analysis}

Typical hyperbenthic and epibenthic species were excluded from the analysis. Furthermore, samples containing maximal one individual were not taken into account for the multivariate analyses ( $n=95$ samples). Descriptive multivariate techniques on fourth root transformed data were used to analyse the community structure: group-averaging cluster analysis based on Bray-Curtis similarity followed by a similarity profile test (SIMPROF, Clarke \& Gorley 2006) and multidimensional scaling (MDS). The main species contributing to the dissimilarity between the significantly $(\mathrm{p}<0.05)$ separated sample groups, resulting from SIMPROF, were identified using the similarity percentage routine (SIMPER, Clarke \& Gorley 2006) and indicator species for each sample group, were identified by Indicator Species Analysis (INDVAL) (Dufrêne \& Legendre 1997). Sample groups were characterized by means of their averaged abundance, species richness, Shannon-Wiener diversity index, taxon composition, feeding group composition and physical habitat characteristics (median grain size, mud content and relative intertidal height). The relationships between community characteristics, community structure and environmental variables were investigated using the BIO-ENV procedure (Clarke \& Gorley 2006) and Spearman rank correlation (Sokal \& Rohlf 1981). Environmental variables and species densities were superimposed on MDS ordination diagrams using 
correlation vectors in order to allow a better visualization of the relation between sample groups, species and environment. Multivariate analyses were performed using the Plymouth Routines In Multivariate Ecological Research (PRIMER) package, version 6 (Clarke \& Gorley 2006).

\begin{tabular}{llcc}
\hline Classis & \multicolumn{1}{c}{ Species } & \multicolumn{2}{c}{ Abbreviation Feeding guild } \\
\hline & & Cer edu & SF \\
Bivalvia & Cerastoderme edule & Mac bal & SDF \\
Bivalvia & Macoma balthica & Scr pla & SDF \\
Bivalvia & Scrobicularia plana & Coll sp & SDF \\
Collembola & Collembola sp. & Orc gam & SDF \\
Crustacea & Orchestia gammarellus & Sph rug & SDF \\
Crustacea & Sphaeroma rugicauda & Hyd ulv & SDF \\
Gastropoda & Hydrobia ulvae & Nema sp. & O \\
Nematoda & Nematoda sp. & Olig sp & SSDF \\
Oligochaeta & Enchytraeidae sp. & Olig sp & SSDF \\
Oligochaeta & Tubificidae sp. & Olig sp & SSDF \\
Oligochaeta & Tubificoides benedeni & Olig sp & SSDF \\
Oligochaeta & Tubifex costatus & Aph mar & SDF \\
Polychaeta & Aphelochaeta marioni & Cap cap & SSDF \\
Polychaeta & Capitella capitata & Ete lon & P \\
Polychaeta & Eteone longa & Ner div & O \\
Polychaeta & Nereis diversicolor & Het fil & SSDF \\
Polychaeta & Heteromastus filiformis & Mal tet & SDF \\
Polychaeta & Malacoceros tetracerus & Pol cor & SDF \\
Polychaeta & Polydora cornuta & SDF \\
Polychaeta & Pygospio elegans & Pyg ele & SDF \\
Polychaeta & Scolelepis squamata & Sco squ & SDF \\
Polychaeta & Streblospio benedicti & Str ben & SDF \\
\hline
\end{tabular}

Table 1. List of macrobenthic species recorded in the Zwin nature reserve during this study. For each species the feeding type is given. SDF; surface deposit feeder, SSDF; subsurface deposit feeder, SF; suspension feeder, O; omnivore, P; predator. Species abbreviations, used in Table 2 and Table 3, are given. 


\section{Results}

\section{General characterization of the macrobenthos}

A total of 23 macrobenthic species were encountered (Table 1). Macrofaunal species richness varied between 0 and 11 spp.sample ${ }^{-1}$, with an average of $3.4 \pm$ $0.21 \mathrm{SE}$ species. The total macrobenthic density ranged from 0 to 71376 ind. $\mathrm{m}^{-2}$, with an average of $7260 \pm 1099$ SE ind. $\mathrm{m}^{-2}$. The most widely distributed species were Nereis diversicolor (Müller 1776)(recorded in $87 \%$ of all samples) and Oligochaeta spp. (75\%). Other species occurred in less than $20 \%$ of the samples.

Total macrobenthic density was dominated by oligochaetes $(60 \%)$ and polychaetes (38\%), while bivalves, arthropods, gastropods and nematodes all contributed to $<1 \%$ of the total density. Based on a feeding guild approach, subsurface deposit feeders dominated the macrobenthos $(71 \%$ of the total macrobenthic density), followed by omnivores/scavengers (20\%), surface deposit feeders $(9 \%)$ and suspension feeders $(<1 \%)$. Five species contributed $96 \%$ of the total macrobenthic density: Oligochaeta spp. (60\%), N. diversicolor (19\%), Heteromastus filiformis (Claparède 1864)(9\%), Aphelochaeta marioni (Saint-Joseph $1894)(6 \%)$ and Capitella capitata (Fabricius 1780)(2\%).

\section{Community structure of the macrobenthos}

Five sample groups (SGs) were significantly separated based on SIMPROF (Fig. 2). Nevertheless, the MDS ordination displayed an overlap between SGs (except for SG 2) and a rather high stress $(0.18)$ which means that not too much reliance should be placed on the details of the plot (Clarke \& Warwick 2001) (Fig. 3). Sample groups 2, 3 and 4 were clearly more diverse as compared to SG 1 and 5 (Table 2). 
Diverse sample groups (SG 2, 3 and 4)

Sample group 2 displayed the highest Shannon-Wiener diversity (1.21 $\pm 0.13 \mathrm{SE})$, followed by SG 3 and 4 (respectively, $1.05 \pm 0.19$ SE and $1.00 \pm 0.06$ SE). Further, in SG 2, averaged species richness was relatively high $\left(7.6 \pm 1.6 \mathrm{SE}\right.$ spp.sample $\left.{ }^{-1}\right)$ in comparison with other SGs and three species had a significant indicator value (IV) > 40: Malacoceros tetracerus (Schmarda 1861), Pygospio elegans (Claparède 1863) and A. marioni. These three surface deposit feeding species reached their highest densities in SG 2 (respectively, $841 \pm 476$ SE ind. $m^{-2}, 163 \pm 47$ SE ind. $m^{-2}$ and $5622 \pm 4754$ SE ind. $\mathrm{m}^{-2}$ ) and can be considered highly indicative for this SG. SG 3 and SG 4 were numerically dominated by Oligochaeta spp., while A. marioni was far less abundant in these SGs (Table 2). Consequently, Oligochaeta spp. and A. marioni contributed largely to the dissimilarity between SG 3, 4 and SG 2 (Table 3). The dissimilarity between SG 3 and 4 was mainly determined by the subsurface deposit feeder $C$. capitata $(C \%=20.7$; see Table 3$)$. This species reached its highest density in SG $3\left(1688 \pm 877\right.$ SE ind. ${ }^{-2}$, i.e. $21 \%$ of the total density), while it was absent in SG 4. INDVAL analysis revealed significant IVs > 40 for C. capitata and Polydora cornuta (Bosc 1802) in SG 3, while Scrobicularia plana (da Costa 1778) and Oligochaeta spp., were highly indicative for SG 4 (IV $=44$ and 35 , respectively).

Less diverse sample groups (SG 1 and 5)

SG 1 and 5 were characterized by a low macrobenthic diversity (species richness $=1.6 \pm 0.2$ SE spp.sample ${ }^{-1}$ and $2.6 \pm 0.2$ SE spp.sample ${ }^{-1}$, respectively for SG 1 and SG 5; Shannon-Wiener diversity $=0.25 \pm 0.09 \mathrm{SE}$ and $0.53 \pm 0.06 \mathrm{SE}$, respectively for SG 1 and SG 5). Furthermore, the lowest macrobenthic density (716 \pm 108 SE ind. $\mathrm{m}^{-2}$ ) was found in SG 1 (Table 2). Oligochaeta spp. numerically dominated SG $5\left(6878 \pm 2304 \mathrm{SE}\right.$ ind. $\mathrm{m}^{-2}$, i.e. $90 \%$ of the total density), while oligochaetes were absent in SG 1. Consequently, Oligochaeta spp. contributed largely (i.e. 53\%, SIMPER, Table 3) to the dissimilarity between both SGs. SG 5 was further 
characterized by the highest densities of the mobile species Hydrobia ulvae (Pennant 1977), Orchestia gammarellus (Pallas 1766) and Collembola spp. The latter two species occurred exclusively in SG 5.

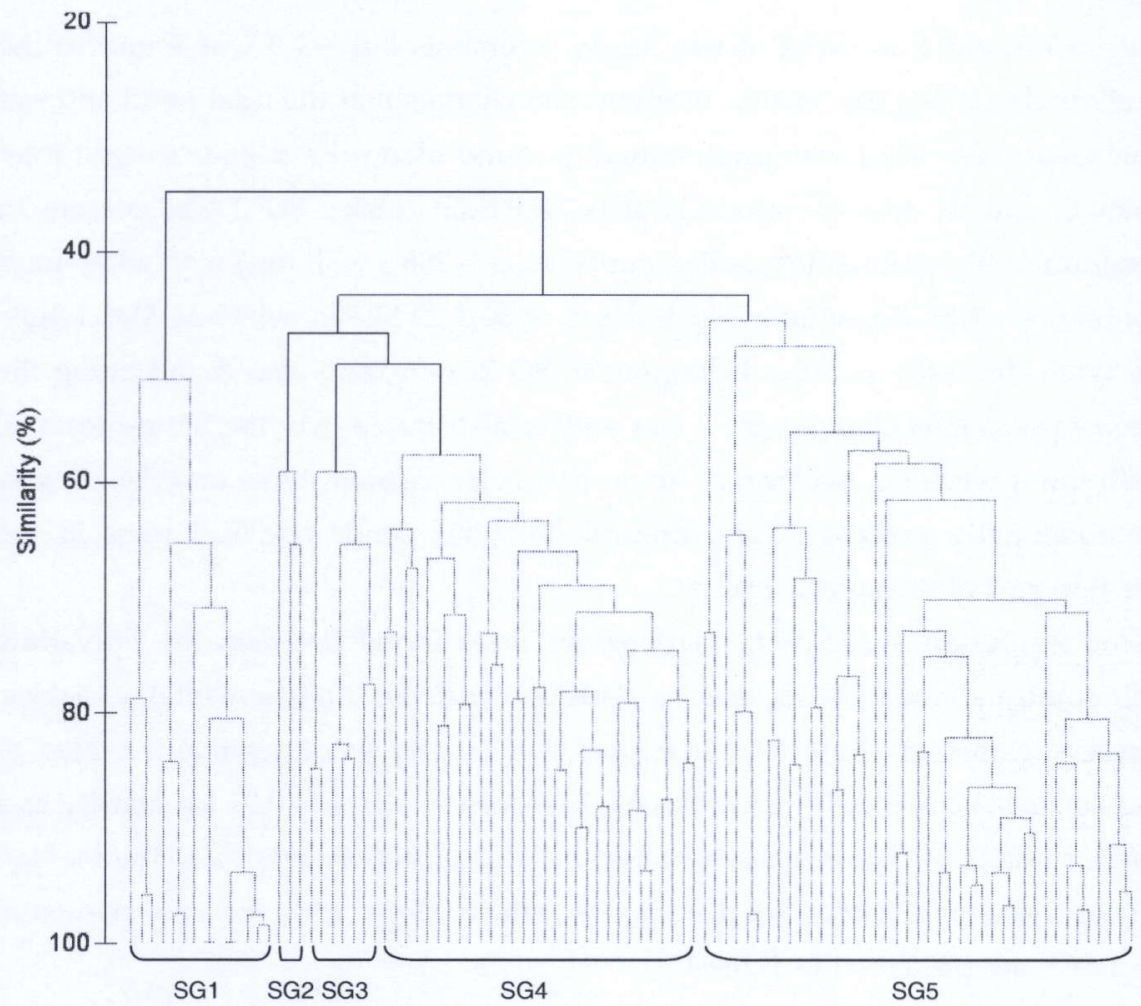

Fig. 2. Dendrogram representing the group average linking cluster analysis based on fourth root transformed macrobenthos density data. The five sample groups (SGs), identified by SIMPROF are indicated by the solid lines and brackets.

\section{Distribution and relations with the abiotic environment}

BIO-ENV revealed a weak correlation between the macrobenthic community structure and the environmental variables: the combination of median particle size and relative intertidal height only explained $0.1 \%$ of the biotic structure in 
the multidimensional space. Nevertheless, in general, distinct distribution patterns, often corresponding with different habitat types (i.e. large tidal inlets, small to medium sized creeks, flats, tidal pond or salt pans) were found for the SGs.

Both SG 3 and 4 occurred in fine sandy sediments but SG 3 was found in the shallow flats along the smaller western inlet channel and the tidal pond and salt pan area while SG 4 was predominantly found along the deeper eastern inlet channel and its adjacent muddier flats and tidal creeks. SG 2 was present in medium sandy sediments (median particle size $=286 \pm 5 \mathrm{SE} \mu \mathrm{m}$ ) with a low mud content ( $4 \pm 2$ SE \%), at an average depth of $50 \pm 29$ SE $\mathrm{cm}$ below MHMS (Table 2). From the three samples belonging to SG 2, two were also found along the deep eastern inlet channel. SG 5 was widely distributed over the nature reserve, with no prevailing occurrence to a particular habitat type and SG 1 was predominantly present in and around the tidal ponds and salt pans in the western part of the nature reserve.

Some weak, but significant, relationships were found between the univariate community characteristics, species densities and the environmental variables. Species richness and the total macrobenthos density were positively related to the distance below MHWS and the median particle size $(r=0.21$ for density and species richness). The species richness was also positively related to the median particle size $(r=0.29)$. Species specific relationships with the environmental variables are presented in Table 4.

\section{Discussion}

Macrobenthos community structure, species richness, density and species densities were found to be related to the mud content, median particle size and relative intertidal elevation of the samples. This is consistent with literature, indicating the importance of sediment characteristics and hydrodynamic conditions (e.g. submersion time, current velocities) in the distribution of macrobenthic communities in estuarine intertidal habitats (e.g. Warwick et al. 
1991, Ysebaert et al 2003). However, correlation coefficients were relatively low. This may partly result from the unreplicated sampling design, given the high small-scale patchiness within the macrobenthos in intertidal areas. Further, other variables may explain the distribution of the distinguished species assemblages as well. Based on a review of $>50$ studies, Snelgrove \& Butman (1994) pointed out that although grain size is usually correlated with the benthic distribution patterns, this correlation is not solely due to grain size alone but also to other variables, related to grain size, such as organic matter content. In addition, salinity conditions and ecological interactions (e.g. predation pressure) can explain macrobenthic distribution patterns in tidal flat habitats (Ysebaert et al. 2003, Williams et al. 2004, Beukema \& Dekker 2005).

Sample group 2 and especially SG 4 were here considered ecologically most important because their high species richness and density of larger macrobenthic species (e.g. 2860 ind. $N$. diversicolor $\mathrm{m}^{-2}, 126$ ind. S. plana $\mathrm{m}^{-2}$ and 24 ind. $M$. balthica $\mathrm{m}^{-2}$ ), which may be expected to contribute most to the waders' diet (Cramp \& Simmons 1977). Other typical species for SG 2 and 4 were A. marioni, M. tetracerus, S. plana and P.elegans. In comparison with the polyhaline tidal flat areas further upstream the Schelde estuary, species composition, total density and diversity is quite similar (Ysebaert et al. 2003, C. Van Colen unpublished data) and similar species assemblages have commonly been observed in similar estuarine environments (e.g. Beukema 1976, 1981, Dörjes et al. 1986). Sample groups 2 and 4 were mainly found within the entrance channel and adjacent wider creeks at the eastern part of the Zwin nature reserve. Contrary to the habitats of the other SGs, this system is characterized by relatively strong tidal currents guaranteeing water renewal at each high tide. This creates a consequent relatively stable highly productive environment in which biomass can accumulate in larger organisms (i.e. k-strategists) (Gamito 2006), compared to the lesser (shallow flats, i.e. SG 3) and erratically submersed and thus stressed areas (SG 1 and SG 5, i.e. tidal pond and salt pan). Given its high macrobenthic value, the extension of wide, tidal creeks should be a prime target within the future development and management of the nature reserve. 


\begin{tabular}{|c|c|c|c|c|c|c|c|c|c|c|}
\hline \multirow[b]{2}{*}{ Environment } & \multicolumn{2}{|c|}{ SG 1} & \multicolumn{2}{|l|}{ SG 2} & \multicolumn{2}{|l|}{ SG 3} & \multicolumn{2}{|l|}{ SG 4} & \multicolumn{2}{|l|}{ SG 5} \\
\hline & & & & & & & & & & \\
\hline Median particle size & $245(23)$ & & $286(5)$ & & $227(29)$ & & $158(16)$ & & $135(16)$ & \\
\hline Mud content & $16(6)$ & & $4(2)$ & & $17(7)$ & & $28(4)$ & & $42(4)$ & \\
\hline Relative intertidal height & $32(9)$ & & $50(29)$ & & $7(7)$ & & $53(10)$ & & $20(4)$ & \\
\hline \multicolumn{11}{|l|}{ Macrobenthos } \\
\hline$S$ (total) & 6 & & 13 & & 8 & & 15 & & 14 & \\
\hline $\mathrm{S}$ (mean) & $1.6(0.2)$ & & $7.6(1.6)$ & & $5.1(0.6)$ & & $5.1(0.2)$ & & $2.6(0.2)$ & \\
\hline $\mathrm{N}$ & $716(108)$ & & $\begin{array}{l}10718 \\
(4894)\end{array}$ & & $\begin{array}{c}8160 \\
(1529)\end{array}$ & & $\begin{array}{l}11275 \\
(1743)\end{array}$ & & $\begin{array}{c}7649 \\
(2285)\end{array}$ & \\
\hline$H^{\prime}(\mathrm{e})$ & $\begin{array}{c}0.25 \\
(0.09)\end{array}$ & & $1.21(0.13)$ & & $1.05(0.19)$ & & $1.00(0.06)$ & & $0.53(0.06)$ & \\
\hline \multicolumn{11}{|l|}{ Top 10 density } \\
\hline & Ner div & $\begin{array}{c}64 \\
6\end{array}$ & Aph mar & $\begin{array}{c}562 \\
2\end{array}$ & Oli spp. & $\begin{array}{c}282 \\
8\end{array}$ & Oli spp. & $\begin{array}{c}517 \\
5\end{array}$ & Oli spp. & $\begin{array}{c}687 \\
8\end{array}$ \\
\hline & Het fil & 35 & Ner div & $\begin{array}{c}274 \\
3\end{array}$ & Ner div & $\begin{array}{c}238 \\
6\end{array}$ & Ner div & $\begin{array}{c}286 \\
0\end{array}$ & Ner div & 556 \\
\hline & Cap cap & 17 & Het fil & $\begin{array}{c}105 \\
9\end{array}$ & Cap cap & $\begin{array}{c}168 \\
8\end{array}$ & Het fil & $\begin{array}{c}193 \\
2\end{array}$ & Hyd ulv & 98 \\
\hline & Aph mar & 6 & Mal tet & 841 & Het fil & 838 & Aph mar & 194 & Pol cor & 29 \\
\hline & Pol cor & 6 & Cap cap & 190 & Str ben & 210 & Scr pla & 126 & Orc gam ${ }^{\circ}$ & 22 \\
\hline & Pyg ele & 6 & Pyg ele & 162 & Pol cor & 105 & Sph rug & 111 & Cap cap & 16 \\
\hline & & & Pol cor & 135 & Aph mar & 58 & Pyg ele & 79 & Sph rug & 14 \\
\hline & & & Cer edu & 27 & Mal tet & 47 & Nem spp. & 63 & Nem spp. & 10 \\
\hline & & & Ete lon & 27 & & & Ete lon & 50 & Col spp. ${ }^{\circ}$ & 8 \\
\hline & & & Hyd ulv & 27 & & & $\mathrm{Mac} \mathrm{bal}^{\circ}$ & 24 & Het fil & 6 \\
\hline \multicolumn{11}{|l|}{$\begin{array}{l}\text { Relative feeding guild } \\
\text { density }\end{array}$} \\
\hline Surface deposit feeders & $2(1)$ & & $49(15)$ & & $6(3)$ & & $11(3)$ & & $8(2)$ & \\
\hline $\begin{array}{l}\text { Subsurface deposit } \\
\text { feeders }\end{array}$ & $11(5)$ & & $13(3)$ & & $65(7)$ & & $54(4)$ & & $65(5)$ & \\
\hline Omnivores/scavengers & $87(6)$ & & $38(14$ & & $29(7)$ & & $35(5)$ & & $27(7)$ & \\
\hline \multirow[t]{3}{*}{ Indicator species } & & & Mal tet & 88 & Cap cap & 62 & Scr pla & 44 & & \\
\hline & & & Pyg ele & 72 & Pol cor & 44 & Oligo & 35 & & \\
\hline & & & Aph mar & 41 & & & & & & \\
\hline
\end{tabular}

Table 2. Environmental and macrobenthic characterization of the sample groups. Averaged values of all sampling stations per SG are given for median grain size $(\mu \mathrm{m})$, mud content $(\%)$, and relative intertidal height (cm below MHWS), total species richness ( $N$ total), mean species richness ( $N$ mean), total density and density of the 10 most abundant species (ind. $m^{-2}$ ), ShannonWiener diversity index $H^{\prime}(e)$ (nits), feeding guild composition (\%). Standard errors are given in parentheses. Species with a significant Indicator Value $>40$ for a particular SG are presented as well. : unique species for this SG. Species abbreviations are listed in Table 1. 

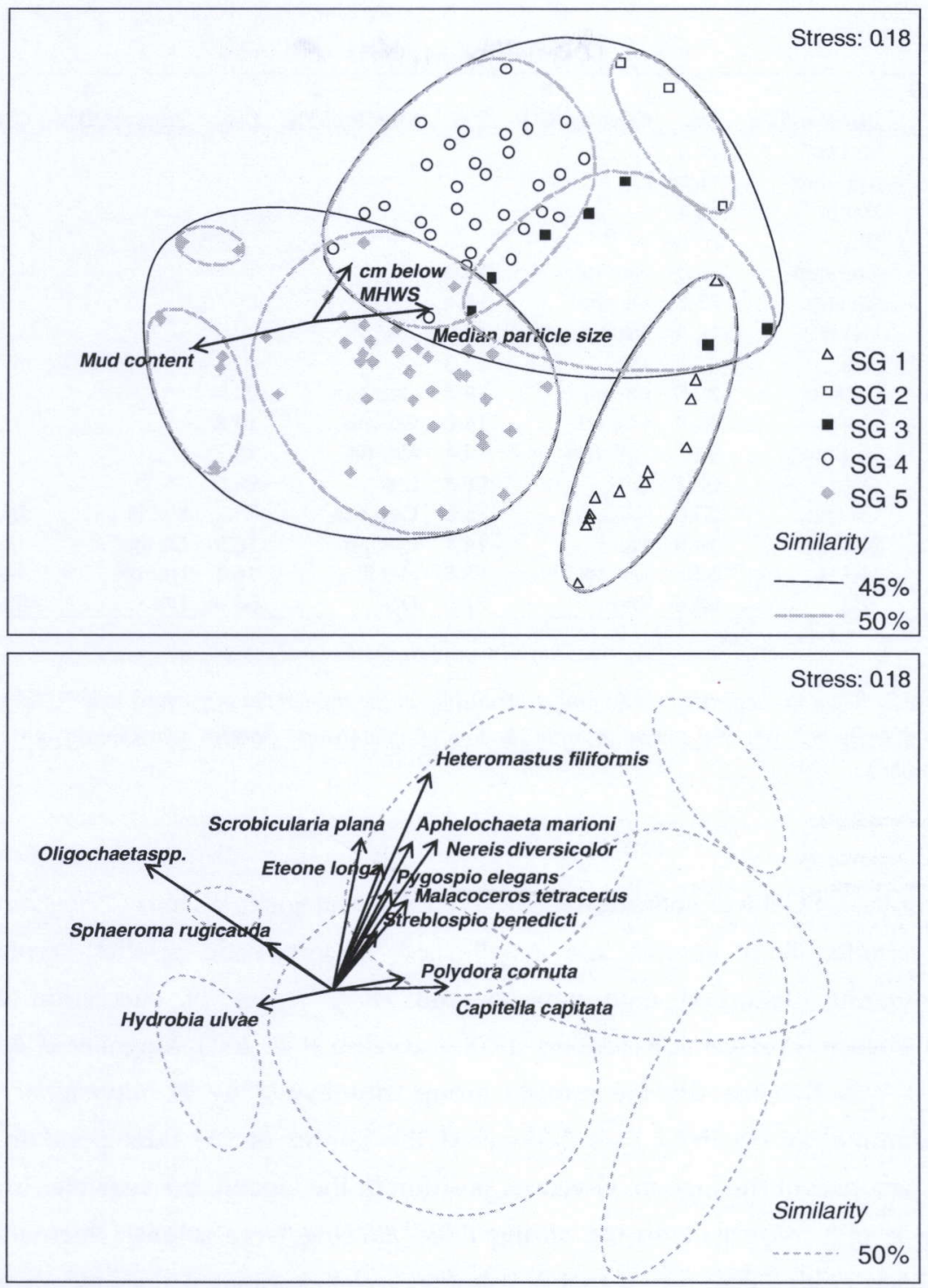

Fig. 3. (a) Multidimensional scaling (MDS) ordination plot of the macrobenthos community structure, based on bray-curtis similarity of fourth root transformed species densities. The significantly separated sample groups by SIMPROF, are indicated by different symbols. Similarity clusters ( $45 \%$ and $50 \%$ ) and correlation vectors of the mud content, median particle size and relative intertidal height are superimposed in (a), 50\% similarity clusters and species correlations $>0.25$ are superimposed in $(b)$. 


\begin{tabular}{|c|c|c|c|c|c|c|c|c|}
\hline \multirow[t]{2}{*}{ SG } & \multicolumn{2}{|l|}{1} & \multicolumn{2}{|l|}{2} & \multicolumn{2}{|l|}{3} & \multicolumn{2}{|l|}{4} \\
\hline & Species/D\% & $\mathrm{C} \%$ & Species/D\% & $\mathrm{C} \%$ & Species/D\% & $\mathrm{C} \%$ & Species/D\% & $\mathrm{C} \%$ \\
\hline \multirow[t]{4}{*}{2} & Mal tet & 17.4 & & & & & & \\
\hline & Aph mar & 16.8 & & & & & & \\
\hline & Het fil & 16.2 & & & & & & \\
\hline & $\mathrm{D} \%$ & 70.0 & & & & & & \\
\hline \multirow[t]{4}{*}{3} & Cap cap & 25.0 & Aph mar & 15.0 & & & & \\
\hline & Oli spp. & 23.6 & Oli spp. & 14.4 & & & & \\
\hline & Het fil & 16.4 & Mal tet & 13.9 & & & & \\
\hline & $\mathrm{D} \%$ & 63.0 & $\mathrm{D} \%$ & 53.6 & & & & \\
\hline \multirow[t]{4}{*}{4} & Oli spp. & 30.6 & Oli spp. & 18.7 & Cap cap & 20.7 & & \\
\hline & Het fil & 20.0 & Mal tet & 14.8 & Oli spp. & 14.8 & & \\
\hline & Ner div & 9.6 & Aph mar & 14.4 & Ner div & 10.7 & & \\
\hline & $\mathrm{D} \%$ & 67.8 & $\mathrm{D} \%$ & 52.8 & $\mathrm{D} \%$ & 50.2 & & \\
\hline \multirow[t]{4}{*}{5} & Oli spp. & 53.0 & Oli spp. & 15.6 & Cap cap & 24.2 & Het fil & 23.2 \\
\hline & Ner div & 14.8 & Het fil & 14.1 & Oli spp. & 18.9 & Oli spp. & 14.6 \\
\hline & Het fil & 6.6 & Mal tet & 13.6 & Het fil & 16.1 & Ner div & 14.3 \\
\hline & $\mathrm{D} \%$ & 63.4 & $\mathrm{D} \%$ & 77.5 & $\mathrm{D} \%$ & 58.4 & $\mathrm{D} \%$ & 53.6 \\
\hline
\end{tabular}

Table 3. Total dissimilarity $(D \%)$ and contribution of the three most important taxa $(C \%)$ to the dissimilarity between any combination of the five sample groups. Species abbreviations are listed in Table 1.

In contrast, SG 3 was characterized by typical r-strategists, such as C. capitata and $P$. cornuta. Both species are small-sized opportunistic species, typically dominating disturbed environments and early stages of succession after disturbance (Pearson \& Rosenberg 1978, Carvalho et al. 2005, Magni et al. 2005). SG 1 was the less diverse sample group, dominated by $N$. diversicolor and predominantly occurred in sediments at the border of the tidal pond in the western part of the lagoon. Given its position in the lagoon, the seawater in this area is only refreshed during spring tides, causing large salinity fluctuations. Ysebaert et al. (2003) found that Nereis diversicolor dominated the macrobenthic community of the meso/oligohaline transition zone of the Schelde estuary. This zone is subject to large, seasonal salinity fluctuations. Hence, $N$. diversicolor can be considered as a species capable to cope with this variability. 


\begin{tabular}{lccc}
\hline \multicolumn{1}{c}{ Species } & $\begin{array}{c}\text { Median particle } \\
\text { size }\end{array}$ & $\begin{array}{c}\text { Mud } \\
\text { content }\end{array}$ & $\begin{array}{c}\text { Relative intertidal } \\
\text { height }\end{array}$ \\
\hline Aphelochaeta marioni & 0,10 & $-\mathbf{0 , 3 2}$ & 0,01 \\
Capitella capitata & 0,09 & $-\mathbf{0 , 3 7}$ & $-0,01$ \\
Cerastoderma edule & $\mathbf{- 0 , 2 6}$ & $-0,17$ & $-0,05$ \\
Collembola spp. & $-\mathbf{0 , 2 6}$ & $-0,02$ & $-0,16$ \\
Eteone longa & $-0,02$ & $-\mathbf{0 , 2 2}$ & $\mathbf{0 , 2 3}$ \\
Hediste diversicolor & 0,03 & $-0,08$ & 0,16 \\
Hydrobia ulvae & $-\mathbf{0 , 3 2}$ & 0,05 & $-0,09$ \\
Macoma balthica & $-\mathbf{0 , 2 1}$ & $-\mathbf{0 , 2 3}$ & 0,08 \\
Malacoceros tetracerus & 0,03 & $-\mathbf{0 , 3 4}$ & 0,01 \\
Nematoda spp. & $\mathbf{- 0 , 2 7}$ & $-0,05$ & 0,02 \\
Nereis diversicolor & 0,13 & $-\mathbf{0 , 3 1}$ & $\mathbf{0 , 2 2}$ \\
Oligochaeta spp. & $-\mathbf{0 , 3 0}$ & 0,23 & $-0,01$ \\
Orchestia gammarellus & $\mathbf{- 0 , 2 8}$ & 0,01 & $-0,16$ \\
Polydora cornuta & 0,05 & $-\mathbf{0 , 3 1}$ & 0,00 \\
Pygospio elegans & 0,00 & $-\mathbf{0 , 3 1}$ & $\mathbf{0 , 3 1}$ \\
Scolelepis squamata & $-\mathbf{0 , 2 5}$ & $-0,17$ & 0,05 \\
Scrobicularia plana & $-0,13$ & $-0,06$ & 0,14 \\
Sphaeroma rugicauda & $-\mathbf{0 , 2 7}$ & $-0,01$ & 0,05 \\
Streblospio benedicti & $-0,14$ & $-\mathbf{0 , 2 1}$ & $-0,10$ \\
\hline
\end{tabular}

Table 4. Spearman rank correlations between species densities and environmental variables. Significant correlations are presented in bold.

\section{Conclusion}

The Zwin nature reserve hosts a rich (max. 71376 ind. $\mathrm{m}^{-2}$ ) and species diverse (max. 11 spp.sample ${ }^{-1}$ ) macrobenthic life. Based on multivariate analyses, five significantly different sample groups were detected. Macrobenthic density, species richness and species densities were correlated to sediment median grain size, mud content, elevation, as well as larger landscape features. The wide, tidal inlet channel was identified as ecologically most important because it contained the highest species richness and densities of larger macrobenthic species. The extension of wide, tidal creeks will result in added values in terms of both benthos and birds and should therefore be a prime target within the future development and management of the nature reserve. 


\section{Acknowledgments}

The first author is supported by the Institute for the Promotion of Innovation through Science and Technology in Flanders, Belgium (IWT Vlaanderen). The authors want to thank Jan Soors (INBO) for the help with the determination of oligochaetes, Bart Beuselinck for assisting in sampling and Danielle Schram for processing the granulometric samples. This paper contributes to the Ghent University BBSea Project (GOA 01600705) and the EU Network of Excellence Marbef (GOCE-CT-2003-505446; contribution number 8052). 